\title{
The effect of controlled shot peening on fusion welded joints
}

\begin{abstract}
This work examines the effect of controlled shot peening (CSP) treatment on the fatigue strength of an ASTM A516 grade 70 carbon steel welded joint. Metallurgical modifications, hardness, elemental compositions, and internal discontinuities, such as porosity, inclusions, lack of penetration, and undercut found in treated and untreated fusion welded joints, were characterized. The fatigue results of as-welded and peened skimmed joints were compared. It was observed that the effect of the CSP and skimming processes improved the fatigue life of the fusion weld by $50 \%$ on MMA-welded, $63 \%$ on MIG-welded, and $60 \%$ on TIG-welded samples.
\end{abstract}

Keyword: Controlled shot peening, ASTM A516 grade 70, Fusion welding 